\title{
Comparison of patient perception on gingival depigmentation using scalpel and diode laser
}

\author{
Dr. Desai Urmi ${ }^{1}$, Dr. Rai J. Jasuma ${ }^{2}$, Dr. Dave Deepak ${ }^{3}$, Dr. Rathva Vandana ${ }^{4}$ \\ ${ }^{1}$ (P.G Student, Department of Periodontics, K. M. Shah Dental College and Hospital, Sumandeep Vidyapeeth, India) \\ ${ }^{2}$ (Associate Professor, Department of Periodontics, K. M. Shah Dental College and Hospital, Sumandeep Vidyapeeth, India) \\ 3 (Professor and Head, Department of Periodontics, K. M. Shah Dental College and Hospital, Sumandeep Vidyapeeth, India) \\ ${ }^{4}$ (Associate Professor, Department of Periodontics, K. M. Shah Dental College and Hospital, Sumandeep Vidyapeeth, India)
}

Abstract: The purpose of this study was to compare patient's perception on gingival depigmentation using diode laser and scalpel technique. 20 Patients took part in the study, control sites were treated with a scalpel blade and test sites were treated with Diode laser in contact mode. VAS scale was used for pain perception after surgery. A questionnaire was used to assess esthetics change postoperatively at 1 week and at 3 months, patient's expectation of the procedure and repetition of treatment if needed. $90 \%$ subjects complained of no pain in the laser group whereas $45 \%$ subjects complained of no pain in scalpel technique which showed VAS scale to be statistical significant between the two groups. Comparison of patient opinion regarding the esthetic change, patient expectation and retreatment of the two surgical procedures were at par with one and another. The application of semiconductor diode laser and scalpel procedure appeared to be an effective treatment for gingival melanin hyperpigmentation.

Key words: Diode laser, hyperpigmentation, melanin, scalpel.

\section{Introduction}

The normal color of the oral mucosa is determined by important factors such as the number and size of blood vessels, oxygenation of blood, epithelial thickness, degree of keratinization, and the amount of pigmentation in the tissue.[1] Melanin, carotene, reduced hemoglobin and oxy hemoglobin are main pigments which contribute to the normal color of gingiva.[2]

Complaints of 'black gums' are common among the patients having a very high smile line (gummy smile) and hyperpigmented gingival tissue often forces patients to seek cosmetic treatment.[3] Various depigmentation techniques have been employed, such as scalpel surgery (Ginnwall et al 1966), gingivectomy (Dummet and Bolden 1963), cryosurgery, electrosurgery, chemical agents such as $90 \%$ phenol and $95 \%$ alcohol (Hirschfeld and Hirschfeld 1951), abrasion with diamond burs, Nd:YAG laser, semiconductor diode laser and $\mathrm{CO}_{2}$ laser.

$810 \mathrm{~nm}$ Diode Laser can be used for numerous "fixed" soft tissue procedures including gingival hyperplasia, crown lengthening and hyperpigmentation. The laser energy acts primarily as a means of incision, excision or ablation, having advantages over the scalpel with no bleeding, no sutures and less chance for infection of the wound. [4]

The study was conducted to compare perception of patient's comfort and esthetic outcome for two surgical techniques in the treatment of gingival hyperpigmentation.

\section{Material and Methods}

The participants were selected from the outpatient Department of Periodontics from K. M. Shah Dental College and Hospital, Piparia, Vadodara from May 2012 to January 2013. A split mouth study was conducted and the study design was approved from the Institutional Ethics Committee (IEC), Sumandeep Vidyapeeth.

Inclusion criteria:

Subjects were included in the study if they met the following criteria - a) they had healthy periodontium, b) age should be between 20-40 years of age, c) presence of melanin hyper pigmentation of the anterior labial gingival segment.

Exclusion criteria

Subjects were excluded if they had: - a) presence of systemic diseases, b) pregnancy/lactation and c) tobacco use.

\subsection{Clinical procedure}

A signed informed consent was taken from all patients willing to participate in this study. A total of 40 anterior segments were treated: 20 were randomly assigned to control group and treated with scraping method by scalpel method and the remaining 20 were identified as test sites and treated with diode laser according to split mouth design. Assignment was performed according to flip coin method by co-investigator (R.V). 
Patients underwent periodontal therapy consisting of oral hygiene instructions and full mouth scaling following which, gingival depigmentation was planned from canine to canine in the anterior region. All patients were evaluated by the co-investigators (D.D., R. J.) and all of them followed the given instructions. All the surgical procedures were performed by the primary investigator (D. U.) who was blinded to segment allotment till the commencement of the procedure.

\subsection{Technique \\ Scalpel technique}

After adequate local anesthesia, hyperpigmented gingival areas up to the canine were de-epithelized with a scalpel blade (no. 15) by the Scraping method. (Fig 1) Depigmentation was carried out from the mucogingival junction towards the tip of the interdental papilla. Coe-Pak dressing was placed on the operated site and analgesic was prescribed. $[3,5]$

\section{Laser therapy}

After adequate local anesthesia, hyperpigmented gingival areas up to the canine were de-epithelized using semiconductor diode laser of wavelength $810 \mathrm{~nm}$. The fiber of length $320 \mathrm{~mm}$ was used in the technique. The laser was used in continuous contact mode. (Fig 2) The fiber tip was used short of 1-2mm in 'paint brush' type stroke moving quickly on the epithelial soft tissue. After the adequate epithelial layers were lased Coe-Pak dressing was placed on the operated site and analgesic was prescribed. Maximum time taken was depending on degree of melanin pigmentation. Protective glasses were used by operator, patient and assistant $[3,5]$.

Patients were observed for 3 months. Clinical evaluation was done at the $7^{\text {th }}$ postoperative day and after the $3^{\text {rd }}$ month. A questionnaire was given to each patient after the surgical procedure to be filled at home. The questions pertained to the patient's perception on esthetic change, expectation of treatment and repetition of treatment if required. The Visual Analogue Scale (VAS) was used to evaluate the subjective pain level experienced by each patient within first week postoperatively. It consists of horizontal line $100 \mathrm{~mm} \mathrm{long}$, starting at the left end with the descriptor "no pain" and ending at the right end with "severe pain." Patients were asked to mark the severity of the pain. The distance of this point from the left end of the scale was recorded and used as the VAS score. [3]

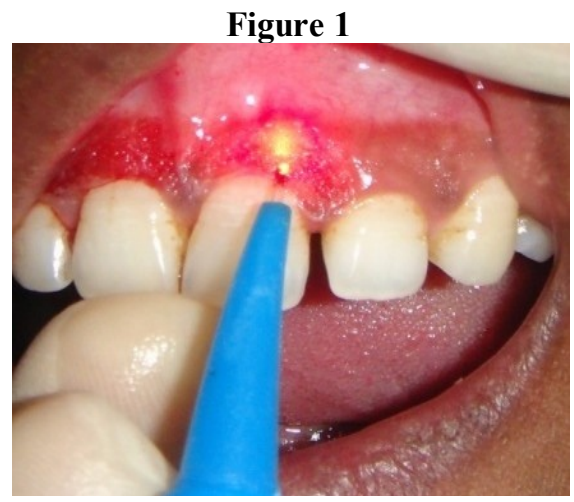

Figure 2

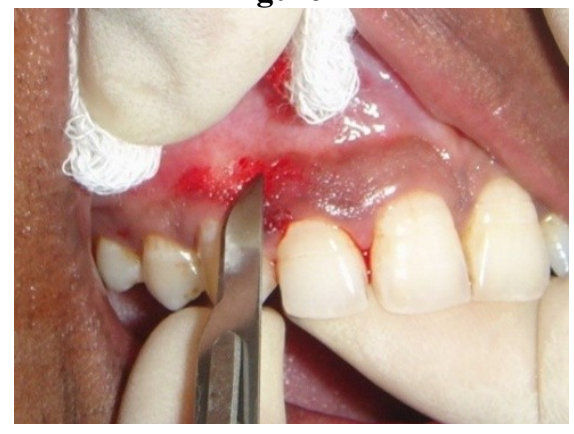

III. Results

20 patients were included in the study in which there were 20 sites of laser group and 20 sites of scalpel group. All the patients completed the study and there were no dropout at the end of $3^{\text {rd }}$ month. Among 20 sites of control (scalpel) group 9 sites $(45 \%)$ had no pain whereas in test (laser) group $18(90 \%)$ sites had no pain. To check the association between two groups with VAS scores, Fisher's exact test was applied. The p-value was 
found to be 0.007. (Table 1) Comparison of VAS score for the two groups was done using Mann-Whitney test. The p-value was found to be 0.011 which shows significant difference of VAS score between laser and scalpel group. (Table 2) In the control group out of 20 sites $11(55 \%)$ sites had sufficient cosmetic change at the end of $1^{\text {st }}$ week after the treatment whereas in the test group $19(95 \%)$ sites had same perception. For comparing two groups, Pearson chi-square test was used and p-value was obtained as 0.008 . There was significant difference between two groups regarding cosmetic change at end of $1^{\text {st }}$ week after treatment. (Table 3)

In the scalpel group $60 \%$ of the sites and in laser group $90 \%$ of the sites had sufficient cosmetic change but showed no significant difference at the end of the $3^{\text {rd }}$ month after treatment. (Table 4) Pearson chi-square test was used to compare expectation regarding treatment and repetition of the procedure between two groups, p-value was found to be 0.487 , and there was no significant difference between two groups. (Table 5, 6)

Table 1: Comparison of VAS Score

\begin{tabular}{|c|c|c|c|}
\hline & & \multicolumn{2}{|c|}{ Group } \\
\hline & & Control & Test \\
\hline \multirow[t]{8}{*}{ VAS } & \multirow[t]{2}{*}{0} & 9 & 18 \\
\hline & & $45.0 \%$ & $90.0 \%$ \\
\hline & \multirow[t]{2}{*}{1} & 2 & 0 \\
\hline & & $10.0 \%$ & $0 \%$ \\
\hline & \multirow[t]{2}{*}{2} & 4 & 2 \\
\hline & & $20.0 \%$ & $10.0 \%$ \\
\hline & \multirow[t]{2}{*}{3} & 5 & 0 \\
\hline & & $25.0 \%$ & $0 \%$ \\
\hline \multirow{2}{*}{\multicolumn{2}{|c|}{ Total }} & 20 & 20 \\
\hline & & $100.0 \%$ & $100.0 \%$ \\
\hline
\end{tabular}

\begin{tabular}{|l|r|r|}
\hline & \multicolumn{1}{|c|}{ Value } & \multicolumn{1}{|c|}{ Exact P-value } \\
\hline Fisher's Exact Test & 10.106 & 0.007 \\
\hline
\end{tabular}

Table 2: Comparison of VAS Score between two groups using Non Parametric Test: Mann-Whitney Test

\begin{tabular}{|c|c|c|c|}
\hline Group & N & Mean Rank & Sum of Ranks \\
\hline Control & 20 & 25.15 & 503.00 \\
\hline Test & 20 & 15.85 & 317.00 \\
\hline Total & 40 & & \\
\hline
\end{tabular}

\begin{tabular}{|l|r|}
\hline & \multicolumn{1}{|c|}{ VAS } \\
\hline Mann-Whitney U & 107.000 \\
\hline Wilcoxon W & 317.000 \\
\hline Z & -3.034 \\
\hline Exact p-value & 0.011 \\
\hline
\end{tabular}

Table 3: Perception of Cosmetic Change at end of $1^{\text {st }}$ week after treatment

\begin{tabular}{|c|c|c|c|}
\hline \multirow{3}{*}{ Q1 } & & \multicolumn{2}{|c|}{ Group } \\
\hline \multirow{3}{*}{ Moderate } & Control & Test \\
\cline { 2 - 4 } & & 9 & 1 \\
\cline { 2 - 4 } & \multirow{3}{*}{ Sufficient } & $45.0 \%$ & $5.0 \%$ \\
\cline { 2 - 4 } & \multirow{2}{*}{ Total } & 11 & 19 \\
\cline { 2 - 4 } & & $55.0 \%$ & $95.0 \%$ \\
\cline { 2 - 4 } & & 20 & 20 \\
\cline { 2 - 3 } & & $100.0 \%$ & $100.0 \%$ \\
\hline
\end{tabular}

\begin{tabular}{|c|c|c|c|}
\hline & Value & df & Exact P-value \\
\hline Pearson Chi-Square & 8.533 & 1 & 0.008 \\
\hline
\end{tabular}


Table 4: Perception of Cosmetic Change at end of $3^{\text {rd }}$ month after treatment

\begin{tabular}{|c|c|c|c|}
\hline \multirow{2}{*}{ Q2 } & & \multicolumn{2}{|c|}{ Group } \\
\hline \multirow{3}{*}{} & Moderate & Control & Test \\
\cline { 3 - 4 } & & 8 & 2 \\
\cline { 2 - 4 } & Sufficient & $40.0 \%$ & $10.0 \%$ \\
\cline { 3 - 4 } & & 12 & 18 \\
\hline \multirow{2}{*}{ Total } & $60.0 \%$ & $90.0 \%$ \\
\cline { 3 - 4 } & & 20 & 20 \\
\cline { 3 - 4 } & & $100.0 \%$ & $100.0 \%$ \\
\hline
\end{tabular}

\begin{tabular}{|l|c|c|c|}
\hline & Value & df & Exact P-value \\
\hline Pearson Chi-Square & 4.800 & 1 & 0.065 \\
\hline
\end{tabular}

Table 5: Perception regarding Expectation of Treatment

\begin{tabular}{|c|c|c|c|}
\hline \multirow{2}{*}{ Q3 } & & \multicolumn{2}{|c|}{ Group } \\
\hline \multirow{3}{*}{} & \multirow{2}{*}{ No } & Control & Test \\
\cline { 3 - 4 } & & 2 & 0 \\
\cline { 3 - 4 } & \multirow{2}{*}{ Yes } & $10.0 \%$ & $0 \%$ \\
\cline { 3 - 4 } & & 18 & 20 \\
\hline \multicolumn{2}{|c|}{ Total } & $90.0 \%$ & $100.0 \%$ \\
\cline { 3 - 4 } & & 20 & 20 \\
\hline \multicolumn{2}{|c|}{} & $100.0 \%$ & $100.0 \%$ \\
\hline
\end{tabular}

\begin{tabular}{|c|c|c|c|}
\hline & Value & df & Exact P-value \\
\hline Pearson Chi-Square & 2.105 & 1 & 0.487 \\
\hline
\end{tabular}

Table 6: Perception regarding Repetition of the Treatment

\begin{tabular}{|c|c|c|c|}
\hline & & \multicolumn{2}{|c|}{ Group } \\
\hline & & Control & Test \\
\hline \multirow[t]{4}{*}{ Q4 } & \multirow[t]{2}{*}{ No } & 4 & 3 \\
\hline & & $20.0 \%$ & $15.0 \%$ \\
\hline & \multirow[t]{2}{*}{ Yes } & 16 & 17 \\
\hline & & $80.0 \%$ & $85.0 \%$ \\
\hline \multirow{2}{*}{\multicolumn{2}{|c|}{ Total }} & 20 & 20 \\
\hline & & $100.0 \%$ & $100.0 \%$ \\
\hline
\end{tabular}

\begin{tabular}{|l|r|r|r|}
\hline & \multicolumn{1}{|c|}{ Value } & \multicolumn{1}{c|}{ df } & \multicolumn{1}{c|}{ Exact P-value } \\
\hline Pearson Chi-Square & 0.173 & 1 & 1.000 \\
\hline
\end{tabular}




\section{Discussion}

Gingival hyperpigmentation is seen as a genetic trait in some population and is more appropriately termed as physiological or racial gingival pigmentation. The prevalence of melanin in different population has been reported to vary between $0 \%$ to $89 \%$ with regard to ethnic factors and smoking habit.[3] Various treatment modalities have been made for cosmetic removal of pigmented area. Chemical solutions such as a mixture of $90 \%$ phenol and $95 \%$ alcohol has been used to destroy tissue down to basal cell layer but the agent is harmful to oral tissue and repigmentation soon develops.[7] Scalpel surgery causes unpleasant bleeding during and after the operation, and it is necessary to cover the exposed lamina propria with periodontal pack for 7 to 10 days. There is a slight predilection for postoperative discomfort in bur abrasion surgeries. [6]

The diode laser causes minimal damage to the periosteum and bone under the gingiva being treated, it has the unique property of being able to remove a thin layer of epithelium cleanly. Although healing of laser wounds is slower than healing of scalpel wounds, the laser wound is sterile and has no inflammatory reaction. Blood vessels in the surrounding tissue up to a diameter of $0.5 \mathrm{~mm}$ are sealed by the laser; thus, the primary advantage is hemostasis and a relatively dry field.[15] The semiconductor diode laser is emitted in continuous wave or gated-pulsed modes, and is usually operated in contact mode using a flexible fiber optic delivery system. Laser light at 800 to $980 \mathrm{~nm}$ is poorly absorbed in water, but highly absorbed in hemoglobin and other pigments.[16] There are many advantages of laser over surgical procedure according to Wigdor et al 1995.[17] These include: 1. Dry and bloodless surgery, 2. Instant sterilization of surgical site, 3. Reduced bacteremia, 4 . Reduced mechanical trauma, 5. Minimal post operative scaring and swelling and 6. Minimal post-operative pain.

Sushma Lagdive et al in 2009 carried out a study to compare semiconductor diode laser to scalpel blade depigmentation. VAS scale was used to evaluate pain and they found out that sites treated with laser had slight or no pain as compared to the other procedure which is in agreement with our study.[3] Haim tal et al in 2003 conducted a study on patient perception on laser therapy. 10 patients were included in the study who filled up a patient evaluation form regarding their perception of pain, discomfort, appearance of gingiva, expectation and repetition of treatment. Patient perception on appearance of gingiva in their study was $96 \%$ which was comparable to the $90 \%$ found in our study in the laser group after a period of 3 months. In their study Haim tal et al found $80 \%$ of patients were pleased with the surgical outcome after $2-4$ weeks. In our study the time period was 3 months and all (100\%) the patients were satisfied with the laser therapy as compared to the scraping method [2]. Though the initial result of the depigmentation surgery is highly encouraging, repigmentation is a common problem. The exact mechanism of repigmentation is not known. This variation may be due to the different techniques performed or due to the patient's race. [13] Thus, gingival depigmentation procedure, if performed primarily for cosmetic reason, will not be of permanent value, because pigmentation tends to return to recur. In the present study, no repigmentation occurred in any of the treated patients. The limitation of the study is the short follow up period ( 3 months) hence this result is not predictive for future, hence more clinical randomized controlled clinical trials are required.

\section{Conclusion}

Growing aesthetic need requires the removal of hyperpigmented areas to create pleasant and confident smile which altogether alter personality of an individual. This could be easily attained using many of the methods like cryosurgery, $\mathrm{CO}_{2}$ Laser, diamond bur, diode laser, scalpel technique. Scalpel surgical technique is highly recommended in consideration of the equipment constraints that may not be frequently available in clinics. Healing period for scalpel wounds is faster but it is necessary to cover the exposed gingiva with periodontal dressing for 7 to 10 days which may be an area of concern for some patients. In laser therapy due to coagulation of capillaries, bleeding is decreased or almost bloodless. The surgical area is sterile and it has profound analgesic effect by blocking neural transmission in the tissues. Hence with these advantages of laser therapy over scalpel technique we have conducted the study where we have compared diode laser with scalpel blade therapy and it can be concluded that application of semiconductor diode laser appeared to be effective alternative to management of gingival hyperpigmentation in terms of perception of pain and esthetics.

\section{References}

[1] Holtzclaw D., Toscano J.N., Tal H., A case report - Spontaneous Pigmentation of Non-Pigmented Palatal Tissue after Periodontal Surgery, J Periodontol 2010; 81:172-176.

[2] Tal H., Oegiesser D., Tal M., Gingival depigmentation by Erbium: YAG Laser: clinical observations and patients responses, J Periodontal 2003; 74:1660-1667

[3] Lagdive S., Doshi Y., Marawar P.P., Management of Gingival Hyperpigmentation Using Surgical Blade and Diode Laser Therapy: A Comparative Study, J Oral Laser Applications 2009; 9: 41-47.

[4] S. Pirnat, Versatility of an $810 \mathrm{~nm}$ Diode Laser in Dentistry: An Overview, Journal of Laser and Health Academy 2007; 2007; 4: 19.

[5] Mani A., Mani S., Shah S., Thorat V., Management of Gingival Hyperpigmentation Using Surgical Blade, Diamond Bur and Diode Laser Therapy: A Case Report, J Oral Laser Applications 2009; 9: 227-232. 
[6] Almas K., Almas W., Surgical treatment of melanin- pigmented gingiva; an Esthetic approach, Indian Journal Dental Research, VOL 13, No.2 April-June 2002.

[7] Suthprasertporn S., Treatment of Gingival Melanin Hyperpigmentation by Er,Cr:YSGG Laser: Report of 2 Cases, Thai J Periodont 2007; $1: 46-55$

[8] Humagain M., Nayak D. G., Uppoor U. S., Gingival depigmentation: A case report with review of literature, J Nepal Dent Assoc 2009; 10: 53-56.

[9] Berk G., Atici K., Berk N., Treatment of gingival pigmentation with Er, Cr:YSGG laser, J Oral Laser Application 2005,5:249-253.

[10] Chapman H. R., Kirby-Turner N., Visual/verbal analogue scales: Examples of brief assessment methods to aid management of child and adult patients in clinical practice, British Dent J 2002,8:193

[11] Kanakamedala A.K., Geetha A., Ramakrishnan T. , Emadi P., Management of Gingival Hyperpigmentation by the Surgical Scalpel Technique - Report of Three Cases, J Clin and Diag Res 2010, 4:2341-2346.

[12] Tanuja P., Babu B. K.,Krishna M., Laser-assisted crown lengthening and gingival depigmentation to enhance aesthetics-a case report, Annals and Essences of Dentistry 2011:4

[13] Sanjeevni H., Gingival De-Pigmentation: 2 Case Reports, J Medi Pharmac and Biol Sci 2012; 2: 01-04

[14] Gupta G., Management Of Gingival Hyperpigmentation By Semiconductor Diode Laser-A case report, J Cutan And Aesth Surg $2011 ; 4$

[15] Ozbayrak S., Dumlu A., Ercalik-Yalcinkaya S. Treatment of melanin pigmented gingiva and Oral mucosa CO2 laser. Oral Surg Oral Med Oral Pathol Oral Radiol Endoo 2000; 90:14-15.

[16] The Academy of Laser Dentistry. Featured wavelength: diode - the diode laser in dentistry (Academy report) Wavelengths 2000; $8: 13$.

[17] Bhardwaj A., Grover H.S., Sanjay L., Gingival depigmentation with scalpel and diode laser, World Journal Of Dentistry,2012;3:359-362

[18] Vishal S., Subraya B., Santhosh K., Mahalinga B., Comparative Evaluation Of Gingival Depigmentation By Diode Laser And Cryosurgery Using Tetrafluoroethane: 18-Month Follow-Up, Clinical Advances in Periodontics 2012; 2 